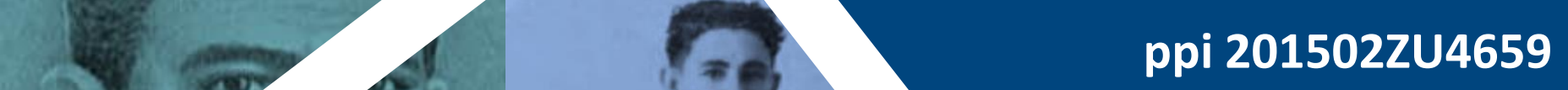

Esta publicación científica en formato digital es continuidad de la revista impresa

SSN 0254-0770/e-ISSN 2477-9377/Depósito legal pp $197802 Z U 38$

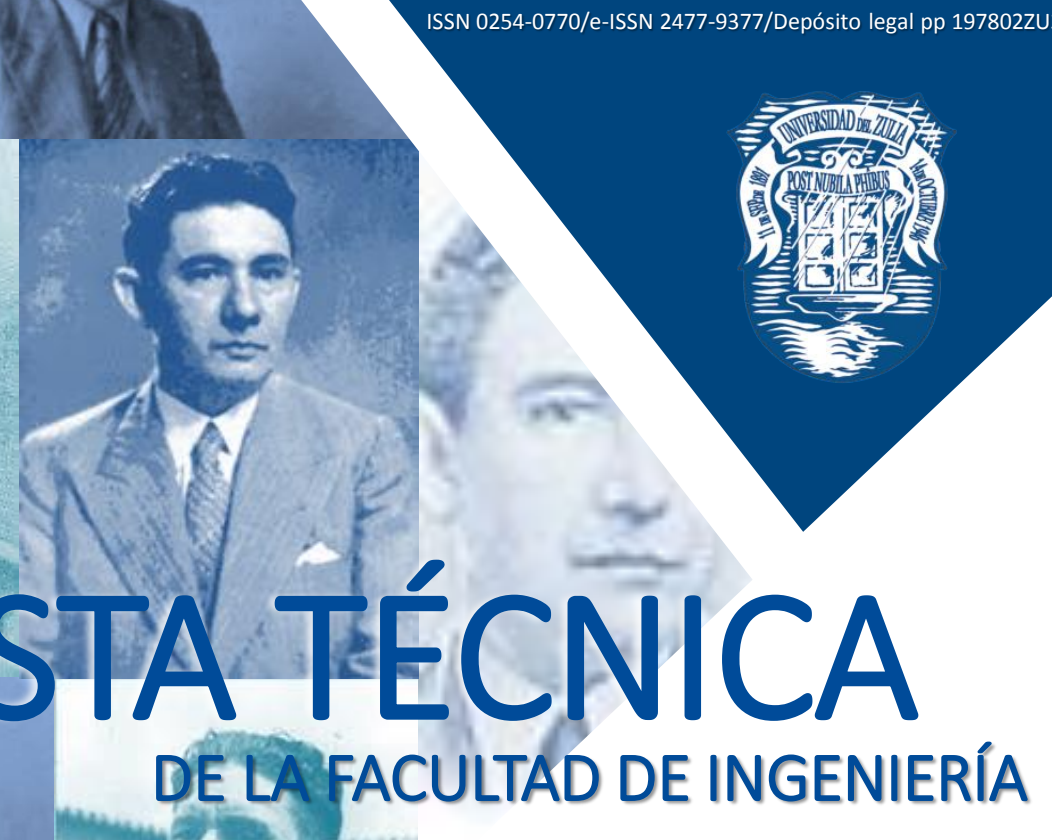
que está indizada en las publicaciones de referencia y comentarios:

- REDALYC

- REDIB

- SCIELO

- DRJI

- INDEX COPERNICUS INTERNATIONAL

- LATINDEX

- DOAJ

- REVENCYT

- CHEMICAL ABSTRACT

- MIAR

- aerospace dATABASE

- CIVIL ENGINEERING ABTRACTS

- METADEX

- COMMUNICATION ABSTRACTS

- ZENTRALBLATT MATH, ZBMATH

- ACTUALIDAD IBEROAMERICANA

- BIBLAT

- PERIODICA

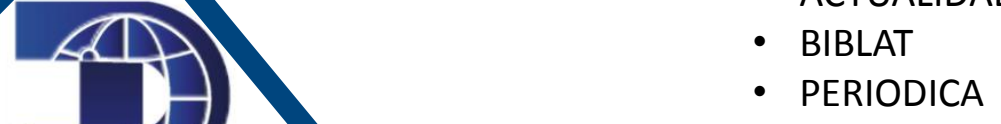




\title{
Identificación de Factores de Operación en un Proceso de Refinación para la Producción de Papel Tisú
}

\author{
Carlos Torres Navarro ${ }^{1 *}$ (D), Vanessa Ortega Zavala ${ }^{1}$ (iD), Sebastián Campos \\ Sáez ${ }^{1}$, Carlos Rozas Mellado ${ }^{2}$ \\ ${ }^{1}$ Departamento de Ingeniería Industrial, Universidad del Bío-Bío, Av. Collao 1202, \\ Concepción, Chile. \\ ${ }^{2}$ Departamento de Ingeniería en Maderas, Universidad del Bío-Bío, Av. Collao 1202, \\ Concepción, Chile. \\ *Autor de correspondencia: ctorres@ubiobio.cl
}

https://doi.org/10.22209/rt.v45n1a03

Recepción: 01 de julio 2020 | Aceptación: 14 de septiembre de 2021 | Publicación: 28 de diciembre de 2021

\begin{abstract}
Resumen
Con la finalidad de lograr un aumento en la rentabilidad de la producción de papel tisú, esta investigación tuvo como objetivo identificar factores que incidan en el grado de refino de la pulpa e índice de tensión del papel tisú al utilizar fibra corta, fibra larga y enzima de refinación Quimizine B. La metodología consideró experimentos en laboratorio, obtención de curvas de refinación, diseño factorial multinivel y diagramas de superficie de respuesta. Los resultados indicaron que el factor común más significativo en el grado de refino de la pulpa e índice de tensión es el consumo específico de energía para ambos tipos de fibra y, que se pueden conocer parámetros óptimos de operación al analizar el grado de refino e índice de tensión en forma independiente y simultánea. Se concluyó que el diseño factorial multinivel permitió identificar factores significativos que influyen en las propiedades del grado de refino y la resistencia del papel tisú cuando se busca un óptimo individual y simultáneo y, que la influencia de la enzima aumentó las propiedades del grado de refino y la resistencia a la tensión del papel al utilizar materia prima de fibra corta y larga de Eucalyptus globulus y Pinus radiata, respectivamente.
\end{abstract}

Palabras clave: análisis factorial multinivel; curvas de refinación; papel tisú; proceso de refinación; superficie de respuesta.

\section{Identification of Operating Factors in a Refining Process for Tissue Paper Production}

\begin{abstract}
In order to achieve an increase in the profitability of tissue paper production, this research aimed to identify factors that affect the degree of pulp refinement and the tension index of the tissue paper when using short fiber, long fiber and Quimizine B enzyme. The methodology considered laboratory experiments, obtaining refining curves, multilevel factorial design and response surface diagrams. The results indicated that the most significant common factor in the pulp refining degree and tension index is the specific energy consumption for both types of fiber, and that optimal operating parameters can be known by analyzing the refining degree and tension index independently and simultaneously. It was concluded that the multilevel factorial design allowed to identify significant factors that influence the properties of the refining degree and the resistance of tissue paper when looking for an individual and simultaneous optimum and, that the influence of the enzyme increased the properties of the refining degree and the tensile strength of the paper when using raw material of short and long fiber from Eucalyptus globulus and Pinus radiata, respectively.
\end{abstract}

Key words: multilevel factor analysis; refining curves; refining process; response surface; tissue paper. 


\section{Identificação de Fatores Operacionais em um Processo de Refino para a Produção de Papel Higiênico}

\section{Resumo}

Com o objetivo de aumentar a rentabilidade da produção de papel higiênico, esta pesquisa teve como objetivo identificar os fatores que afetam o grau de refinamento da polpa assim como o índice de tensão do papel higiênico ao utilizar fibra curta, fibra longa e enzima de Quimizine B refinamento. A metodologia considerou experimentos de laboratorio, obtenção de curvas de refino, planejamento fatorial multinível e diagramas de superfície de resposta. Os resultados indicaram que o fator comum mais significativo no grau de refinamento da polpa e índice de tensão é o consumo específico de energía para ambos tipos de fibra e que os parámetros operacionais ideais podem ser conhecidos pela análise do grau de refinamento e índice. Tensão independientemente e simultáneamente. Concluiuse que o planejamento fatorial multinível permite identificar fatores significativos que influenciam nas propriedades do grau de refinamento e da resistência do higienico quando se busca um ótimo individual e simultâneo, e que a influencia de enzima aumentou como propriedades do grau de refinamento e da resistência à tração do papel ao usar matéria-prima de fibra curta e longa de Eucalyptus globulus e Pinus radiata, respectivamente.

Palavras-chave: análise fatorial multinível; curvas de refino; papel higiênico; processo de refino; superfície de resposta.

\section{Introducción}

El origen de esta investigación se fundamenta en la necesidad de mejorar la competitividad de una empresa manufacturera de papel tisú para perfeccionar la resistencia del papel, dado que es una de las características de calidad relevantes en este tipo de producto (Gigac y Fiserova, 2008; Buendía, 2013; Villarreal et al., 2014). El proceso bajo estudio pertenece a una empresa de la industria del papel, ubicada en la provincia de Concepción, Chile, enfocada, entre otros, en la elaboración de productos de papel tisú. El papel tisú es un tipo de papel fino de bajo gramaje y elaborado principalmente de pulpa de celulosa; se utiliza en la fabricación de productos de higiene personal, en el ámbito doméstico y como material sanitario y de limpieza industrial. El segmento de papel tisú no se limita solo a la fabricación de papel, abarca una amplia variedad de otros productos, como pañales y toallas femeninas, y constituye una industria de recursos y mercados diversificados que permiten una variedad en la producción (Coimbra y Lima, 2018). En Luiz da Silva (2005) se afirma que la pulpa de eucalipto proporciona a los papeles tisú una característica de suavidad, muy apreciada por los consumidores. La industria del papel tisú ha tenido que enfrentar algunos desafíos de producción, que reducen su rentabilidad, tales como: una intensa competencia, cambios en las preferencias de los consumidores y una disminución en la disponibilidad de papel reciclado. En este sentido, es importante que los fabricantes encuentren alternativas, por ejemplo, analizar combinaciones de fibra, tecnologías y aditivos, entre otros (De Assis et al., 2019).

El papel tisú se fabrica a partir de fibras de celulosa virgen de Pinus radiata (fibra larga), de Eucaliptus globulus (fibra corta) o de fibras de papel de reproceso (recortes). Las fibras largas añaden al papel propiedades mecánicas como resistencia, rigidez y capacidad de absorción, y las fibras cortas añaden propiedades superficiales como suavidad y opacidad (Valiente, 2013; Aguilar, 2016). El macroproceso de fabricación de papel tisú se divide en cuatro etapas: i) preparación de la pulpa (disgregación, depuración y refinación), ii) mezclado, iii) aproximación de la pulpa, y iv) formación de la hoja de papel. La refinación del papel tisú es un proceso crítico que se caracteriza por aplicar un tratamiento mecánico en un medio acuoso a las fibras de madera, mediante el cual se logran características óptimas en el papel, como por ejemplo, flexibilidad, volumen específico e índice de tensión. El índice de tensión (IT) es la fuerza máxima capaz de soportar una hoja de papel antes de romperse y se mide en newton metro por gramo $(\mathrm{Nm} / \mathrm{g})$. Además, este proceso tiene alta incidencia en el consumo de energía en la planta. El índice de tensión $(\mathrm{Nm} / \mathrm{g})$ es el resultado del cociente entre la tensión $(\mathrm{N} / \mathrm{m})$ y el gramaje sobre la pulpa $\left(\mathrm{g} / \mathrm{m}^{2}\right)(\mathrm{Cadena}$, 2008; Contreras, 2013). Por otra parte, el grado de refino de una pulpa (freeness) es la capacidad de filtración de agua a través de las fibras retenidas en una malla metálica (Angarita et al., 2009; Robles et al., 2014; Delgado et al., 2015). 
El análisis de regresión emplea métodos que permiten determinar la mejor relación funcional entre variables concurrentes. Por su parte, el análisis de correlación estudia el grado de asociación de dos o más variables, donde el coeficiente de determinación se utiliza con frecuencia para juzgar la adecuación de un modelo de regresión. Además, los diseños factoriales son necesarios cuando puede estar presente alguna interacción entre factores, evitando hacer conclusiones engañosas, incluso, permiten estimar los efectos de un factor en diversos niveles de los demás factores, produciendo conclusiones más válidas (Hines et al., 2014; Montgomery, 2019). También, una técnica gráfica efectiva para comparar tendencias entre variables es el uso de curvas de refinación. En este sentido, la revisión bibliográfica permitió identificar la aplicación de curvas de refinación solo para el papel corrugado, y no para el papel tisú (Bassa y Sacon, 2005; Escoto et al., 2010; Parra, 2011; Escoto et al., 2015; Colson et al., 2016). Según Bhat (2000), los diseños factoriales multinivel son las técnicas más adecuadas para estudiar los efectos producidos por dos o más factores, ya que así se puede encontrar un modelo que permita describir el comportamiento general del fenómeno en estudio.

El objetivo de esta investigación fue identificar factores de operación significativos que tienen incidencia en el grado de refino de la pulpa e índices de tensión en el papel tisú al utilizar fibra corta, fibra larga y enzima de refinación Quimizine B. Los objetivos específicos fueron: i) verificar si la variación en el grado de refino de la materia prima, al utilizar fibra larga y fibra corta, presenta un rango aceptable para asegurar confiabilidad en los resultados de las curvas de refinación, ii) identificar los factores más influyentes en los resultados de los índices de tensión y en el grado de refino de la pulpa refinada a la salida del proceso de refinación, y iii) verificar el efecto que produce la aplicación de la enzima de refinación Quimizine B en el grado de refino del producto y en el consumo específico de energía. El alcance de esta investigación está circunscrito al subproceso de refinación de papel tisú con la intención de reunir evidencia empírica sobre las curvas de refinación, evaluar la efectividad de utilizar una determina enzima de refinación y hallar rangos óptimos de trabajo para lograr una mejor eficiencia en el proceso de fabricación de papel tisú. Con el fin de analizar mejores opciones operacionales, se investigó el impacto que genera la agregación de una enzima de refinación, debido a que permitiría reducir el consumo de energía, mejorar las propiedades de resistencia del producto final y el proceso de drenaje del agua, logrando con ello lograr mayores niveles de productividad, de acuerdo con Bhat(2000).

\section{Materiales y Métodos}

\section{Variables bajo estudio}

Las variables de proceso bajo estudio fueron: consumo específico de energía y consistencia de la pulpa, mientras que las variables de respuesta fueron: grado de refino e índice de tensión del papel tisú.

Las identificaciones de las variables de interés, se indican en la Figura 1. La variable de entrada, grado de refino de la materia prima, estuvo constituida por celulosa de Eucaliptus globulus y Pinus radiata. Como variable de proceso, se consideró el consumo específico de energía y la consistencia de la pulpa. El consumo específico de energía corresponde a la energía aplicada a la fibra a través de los discos del refinador, y se mide en mega joule por miligramo.

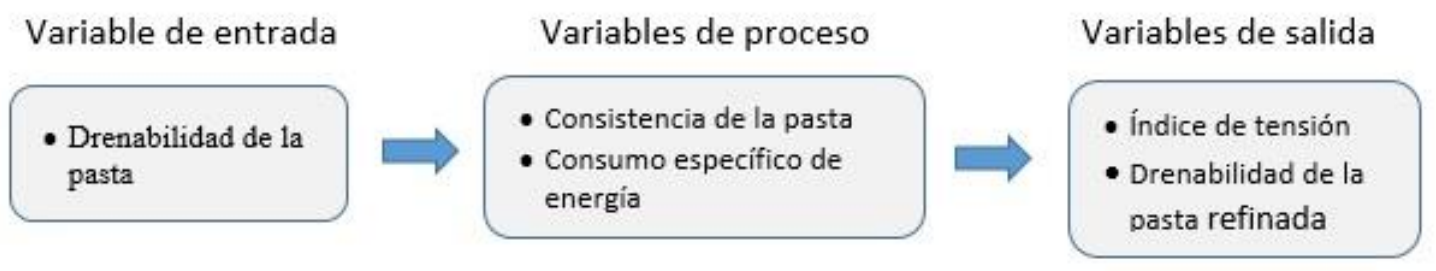

Figura 1. Variables en proceso de refinación de papel tisú.

Como variables de salida, se estudiaron el grado de refino de la pulpa refinada y el índice de tensión, porque se buscaba obtener una pulpa fácil de drenar y un papel con altos valores de resistencia a la tensión. Esto se confirma con lo expuesto por los autores Torres et al. (2005) y De Assis et al. (2019) que aluden que el índice de tensión es una de las propiedades del papel más exigidas en el mercado. 


\section{Procedimiento}

En una primera etapa se tomaron muestras de materia prima (Eucaliptus globulus y Pinus radiata), que fueron rasgadas en trozos e ingresadas en un desintegrador, formándose una pulpa de fibras con agua, que posteriormente fue introducida en el analizador de grado de refino (marca Canadian Standard Freeness Tester, modelo PN-PL26) para determinar el grado de refino, de modo de seguir el método descrito en la norma ISO 5267-2 (2001) y verificar que su coeficiente de variación fuese inferior a $7 \%$ (ISO, 2001). Para este análisis se utilizaron las normas JIS Z 9031 (2012) e ISO 3951-1 (2013), con la finalidad de disponer de datos representativos estadísticamente. El tamaño de las muestras de láminas de celulosa (variable de entrada), estuvo constituida por 108 láminas: 54 muestras de fibra larga y 54 muestras de fibra corta.

Para el caso de la determinación del índice de tensión se utilizó un equipo de medición de resistencia tensión (marca IDM Test, modelo MTC-100), obteniendo dos hojas según la norma ISO 5269-1 (2005).

En una segunda etapa se obtuvieron las curvas de refinación para conocer el efecto sobre los índices de tensión y grado de refino al variar diferentes parámetros de consumo de energía, de niveles de consistencia y utilización de la enzima de refinación Quimizine B (90 g por cada 1,7 toneladas de pulpa, equivalente a un batch o lote), y verificar su influencia en los resultados de tensión y grado de refino del papel tisú al utilizar fibra larga y para fibra corta. Esta metodología dio origen a 72 tratamientos: 18 por cada tipo de fibra durante el proceso de refinación. En la Tabla 1 se presenta la matriz de diseño de factores multinivel respectiva. El orden de las corridas fue aleatorio, con la finalidad de anular la influencia de eventuales errores no controlables en los tratamientos (Gutiérrez y De la Vara, 2012).

Tabla 1. Matriz de diseño - factores experimentales.

\begin{tabular}{lccc}
\hline Tipo de refinado & Uso de enzima & $\begin{array}{c}\text { Niveles de } \\
\text { consistencia } \\
(\mathbf{\%})\end{array}$ & $\begin{array}{c}\text { Niveles de consumo específico de } \\
\text { energía } \\
\mathbf{( m J / m g )}\end{array}$ \\
\hline Con fibra larga & Sin enzima & 3,$5 ; 4,0 ; 4,5$ & $144 ; 180 ; 216 ; 252 ; 288 ; 324$ \\
Con fibra larga & Con enzima & 3,$0 ; 3,5 ; 4,5$ & $144 ; 180 ; 216 ; 252 ; 288 ; 324$ \\
Con fibra corta & Sin enzima & 3,$0 ; 3,5 ; 4,0$ & $144 ; 180 ; 216 ; 252 ; 288 ; 324$ \\
Con fibra corta & Con enzima & 3,$0 ; 3,5 ; 4,0$ & $144 ; 180 ; 216 ; 252 ; 288 ; 324$ \\
\hline
\end{tabular}

Para el procesamiento y análisis de los datos experimentales se utilizó un diseño factorial multinivel, disponible en el programa Statgraphics, versión 18, para estudiar efectos individuales, efectos de interacción, rangos de desempeño óptimos de factores experimentales y disponer de recursos tabulares y gráficas (Statgraphics, 2017). Con la finalidad de identificar soluciones alternativas de operación en el proceso de refinación de la pulpa, se utilizaron diagramas de contorno, los cuales presentan curvas formadas por la intersección de la superficie y un plano paralelo al plano $x y$ en valores específicos de $z$ (Statgraphics, 2017).

\section{Resultados y Discusión}

Los resultados obtenidos en las curvas de refinación se consideran aceptables, ya que la variabilidad en el grado de refino de la materia prima, para fibra corta y fibra larga, presentó coeficientes de variación de 1,08 y 2,03 $\%$, respectivamente. Así, el factor que presenta una mayor influencia o significancia estadística utilizando un nivel de confianza del 95,0 \% en los resultados de los índices de tensión y grado de refino para fibra corta y larga es, en primer lugar, el consumo específico de energía (CEE) como se muestra en aquellos factores que cruzan la línea vertical en los respectivos diagramas de Pareto estandarizados (Figuras 2a, 2b, 3a y 3b). Los demás factores bajo análisis presentaron una significancia estadística diferente, cuando se compararon los resultados del grado de refino e índice de tensión utilizando fibra larga y fibra corta. Por ejemplo, para el caso del índice de tensión (caso fibra larga), el segundo factor más significativo fue la consistencia de la pulpa (B), a diferencia del caso con fibra corta donde el segundo factor más significativo fue el valor cuadrático de la consistencia (BB) (Figura 3a).

Por otra parte, para el caso del índice de grado de refino (caso fibra larga), no se presentaron factores adicionales estadísticamente significativos, con $\alpha=0,05$ (Figura 2b). Para el caso de fibra corta, a diferencia del anterior, se registró un segundo factor principal significativo relacionado con la consistencia de la pulpa (B) (Figura 3b). En ninguno de los casos anteriores fueron influyentes efectos de interacción entre consumo específico de energía 
y consistencia (AB). El efecto cuadrático de la consistencia (AA) no resultó estadísticamente significativo en ninguno de los dos tipos de fibra.

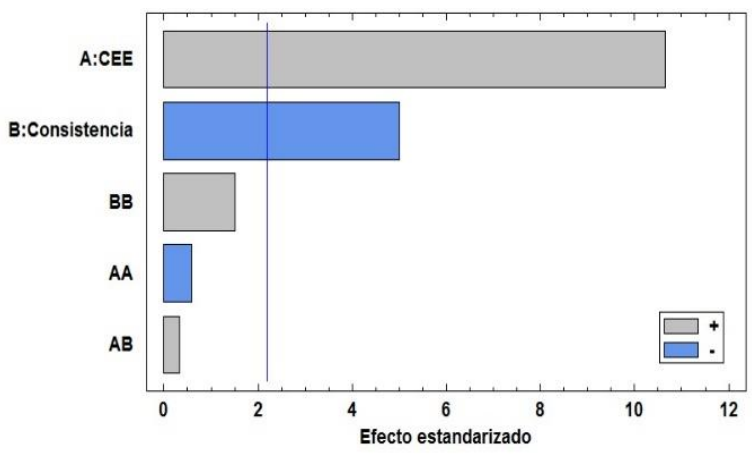

(a)

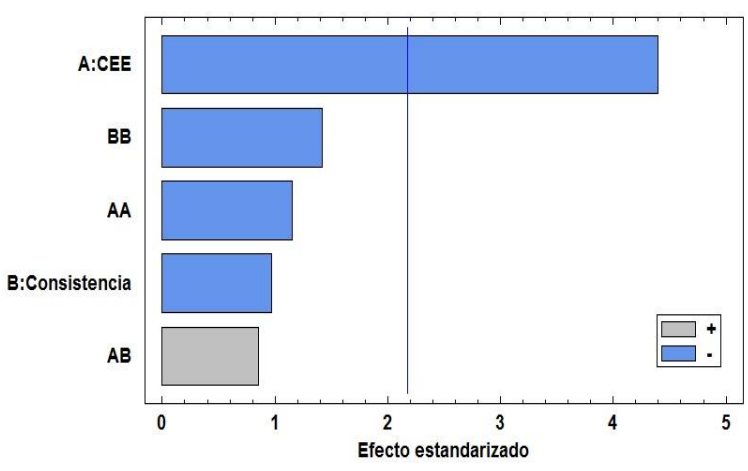

(b)

Figura 2. Diagramas de Pareto estandarizados para índice de tensión (a) y grado de refino (b), caso fibra larga. CEE: consumo específico de energía, BB: efecto cuadrático de consistencia de la pulpa, AA: efecto cuadrático de consumo especifico de energía, AB: interacción entre consumo específico de energía y consistencia de la pulpa.

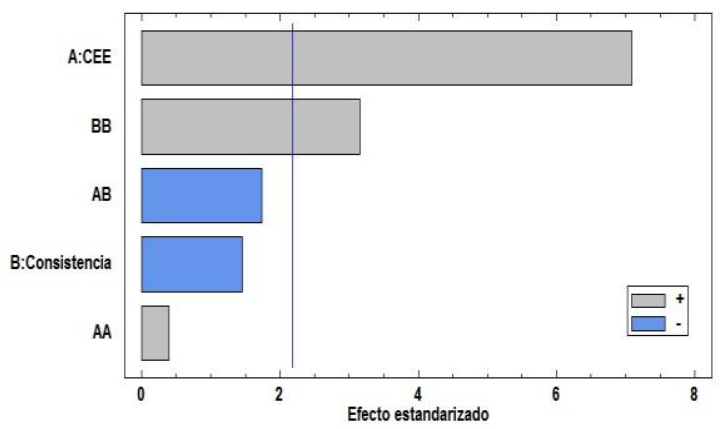

(a)

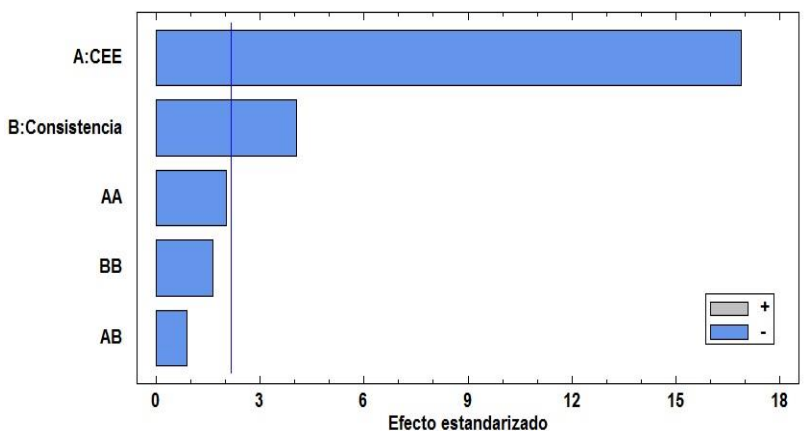

(b)

Figura 3. Diagramas de Pareto estandarizados para índice de tensión (a) y grado de refino (b), caso fibra corta. CEE: consumo específico de energía, BB: efecto cuadrático de consistencia de la pulpa, AA: efecto cuadrático de consumo especifico de energía, AB: interacción entre consumo específico de energía y consistencia de la pulpa.

En las Ecuaciones 1 a 4 se presentan los modelos ajustados para el índice de tensión (IT) y grado de refino (D) para cada tipo de fibra; resultados que permiten realizar estimaciones de sus variables de respuesta ante diferentes valores operacionales de sus variables independientes. En la Tabla 2, por su parte, se presentan los valores óptimos (casos fibra corta y larga) para el grado de refino e índice de tensión, así como los valores óptimos de los factores de consumo específico de energía y consistencia, además del valor del índice de determinación ( $\mathrm{r}^{2}$ ajustado) resultante de cada modelo. Este índice de determinación indica que tan bien se ajusta el modelo a los datos experimentales. De acuerdo con los resultados de $r^{2}$ ajustado (Tabla 2), se puede deducir que los modelos ofrecen un ajuste satisfactorio a los datos. Adicionalmente, la verificación de los supuestos de normalidad, varianza constante e independencia de los residuos, vistas a través de los gráficos de residuos asociados a estos tres supuestos, no mostró un incumplimiento evidente de estos tres supuestos del análisis (Bhat, 2000). Las ecuaciones son:

$$
\begin{aligned}
& \text { IT flarga }=25,61+6,92 * \text { CEE }-2,72 * \text { Consistencia }-0,66 * \mathrm{CEE}^{2}+0,26 * \text { CEE } * \text { Consistencia }+1,43 *
\end{aligned}
$$

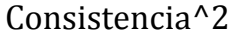

$$
\begin{aligned}
& \text { (1) } \\
& \text { D flarga }=691,03-17,60 * \text { CEE }-3,25 * \text { Consistencia }-7,92 * \operatorname{CEE}^{\wedge} 2+4,18 * \text { CEE } * \text { Consistencia }- \\
& 8,25 * \text { Consistencia^}^{\wedge} 2 \\
& \text { IT f corta }=38,50+3,89 * \text { CEE }-0,67 * \text { Consistencia }+0,37 * \mathrm{CEE}^{\wedge} 2-1,17 * \mathrm{CEE} * \text { Consistencia }+ \\
& 2,51 * \text { Consistencia^ } 2
\end{aligned}
$$




\section{D $f$ corta $=506,75-39,05 *$ CEE $-7,83 *$ Consistencia $-8,04 * \mathrm{CEE}^{2}-2,5 *$ CEE $*$ Consistencia $-5,5 *$ Consistencia^2

Donde: $\mathrm{IT}_{\text {farga }}$ es el índice de tensión fibra larga, $\mathrm{D}_{\text {flarga }}$ grado de refino fibra larga, $\mathrm{IT}_{\text {fcorta }}$ índice de tensión fibra corta, $\mathrm{D}_{\text {fcorta }}$ grado de refino fibra corta y CEE consumo específico de energía.

Tabla 2. Valores óptimos para índice de tensión y grado de refino (fibras corta y larga).

\begin{tabular}{lccccc}
\hline Tipo de fibra & $\begin{array}{c}\text { Consumo específico } \\
\text { de energía }(\mathbf{m J} / \mathbf{m g})\end{array}$ & $\begin{array}{c}\text { Consistencia } \\
(\mathbf{\%})\end{array}$ & $\begin{array}{c}\text { Grado de } \\
\text { refino }(\mathbf{m l})\end{array}$ & $\begin{array}{c}\text { Índice de tensión } \\
\mathbf{( N m} / \mathbf{g})\end{array}$ & $\begin{array}{c}\mathbf{r}^{\mathbf{2}} \text { ajustado } \\
\mathbf{( \% )}\end{array}$ \\
\hline Fibra corta & 144 & 3,5 & 539,1 & & 96,3 \\
Fibra corta & 324 & 3,0 & & 47,1 & 84,5 \\
Fibra larga & 324 & 3,5 & & 35,8 & 92,1 \\
Fibra larga & 198 & 3,5 & 702,4 & & 67,0 \\
\hline
\end{tabular}

En las Figuras 4 y 5 se presentan los diagramas de contorno de superficie de respuesta (con regiones pintadas) del índice de tensión y grado de refino, para los casos de utilización de fibra larga y corta en el refinador. Éstos complementan gráficamente la información de la Tabla 2. En particular, al observar la Figura 4a, se deduce que para lograr un máximo valor en el índice de tensión $(35,8 \mathrm{Nm} / \mathrm{g})$ al utilizar fibra larga, la consistencia debe estar en su nivel bajo $(3,5 \%)$ y el consumo específico de energía en su nivel alto $(324 \mathrm{~mJ} / \mathrm{mg})$, mostrando además, que la zona del máximo valor del índice de tensión se encuentra en la esquina inferior derecha. El valor máximo del grado de refino $(702,4 \mathrm{ml})$ se logra con un nivel bajo de consistencia $(3,5 \%)$ y con un consumo específico de energía en su nivel $-0,45(198 \mathrm{~mJ} / \mathrm{mg}$ ), es decir, en la zona inferior izquierda (Figura $4 \mathrm{~b}$ ).

Análogamente, se deduce de la Figura 5a, que para lograr un máximo valor en el índice de tensión $(47,1$ $\mathrm{Nm} / \mathrm{g}$ ) al utilizar fibra corta, la consistencia debe estar en su nivel bajo $(3,0 \%)$ y el consumo específico de energía en su nivel alto $(324 \mathrm{~mJ} / \mathrm{mg})$, observándose que el valor máximo del índice de tensión se encuentra en la zona inferior derecha. En cuanto al valor máximo del grado de refino $(539,1 \mathrm{ml})$, el mismo se logra con una consistencia en su nivel $-0,49(3,2 \%)$ y con un consumo específico de energía en su nivel bajo $(144 \mathrm{~mJ} / \mathrm{mg})$, es decir, en la zona inferior izquierda.

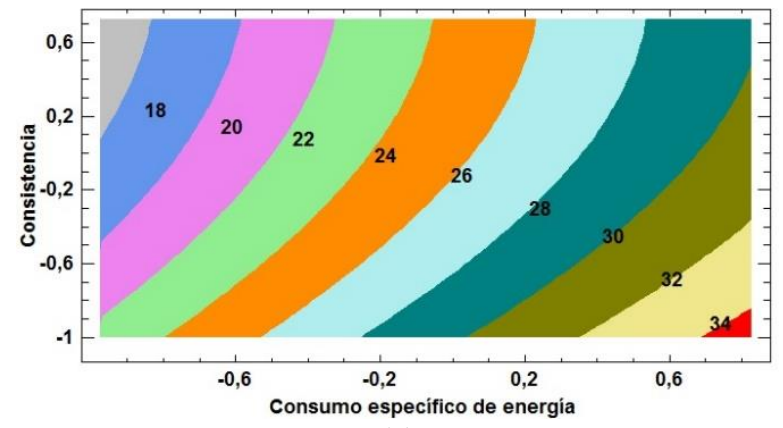

(a)

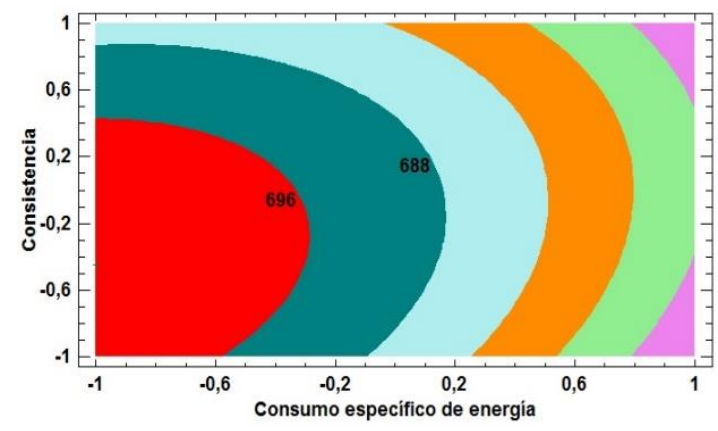

(b)

Figura 4. Superficie de respuesta estimada para índice de tensión (a) y grado de refino (b) con fibra larga.

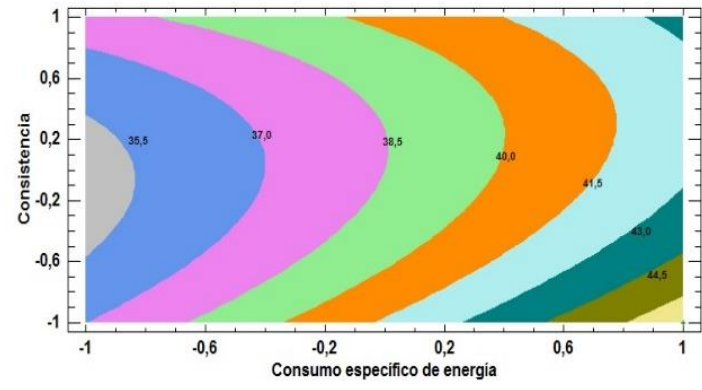

(a)

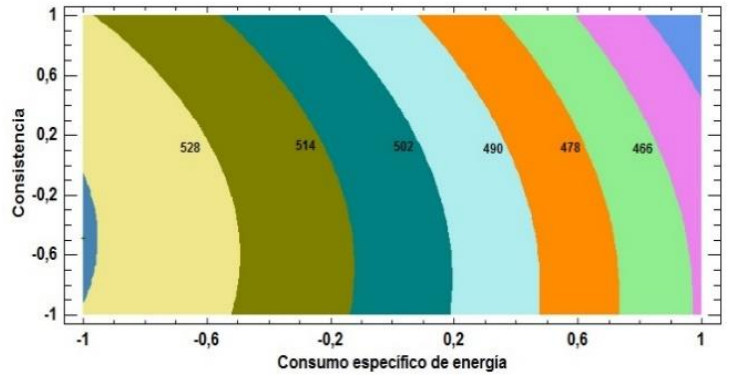

(b)

Figura 5. Superficie de respuesta para índice de tensión (a) y grado de refino (b) con fibra corta. 
En la Tabla 3 se presentan los valores óptimos simultáneos de las variables independientes y de respuesta que maximizan las funciones de deseabilidad para ambos tipos de fibra.

Tabla 3. Valores óptimos simultáneos que maximizan las funciones de deseabilidad.

\begin{tabular}{lcccc}
\hline Tipo de fibra & $\begin{array}{c}\text { Consumo específico de } \\
\text { energía, nivel [valor] }\end{array}$ & $\begin{array}{c}\text { Consistencia, } \\
\text { nivel [valor] }\end{array}$ & $\begin{array}{c}\text { Índice de tensión } \\
(\mathbf{N m} / \mathbf{g})\end{array}$ & $\begin{array}{c}\text { Grado de refino } \\
(\mathbf{m l})\end{array}$ \\
\hline Fibra larga & $0,04[243,4 \mathrm{~mJ} / \mathrm{mg}]$ & $-1[3,5 \%]$ & 30,03 & 685,10 \\
Fibra corta & $0,31[178,6 \mathrm{~mJ} / \mathrm{mg}]$ & $-1[3,0 \%]$ & 43,27 & 497,10 \\
\hline
\end{tabular}

La función de deseabilidad consiste en definir una función en el espacio de los factores que estima una deseabilidad global del producto en cada punto, de modo que convierte un problema de optimización multivariado en uno de optimización univariado. Al respecto, Ivanovna y López (2018) indicaron que el uso de las funciones de deseabilidad ha sido ampliamente adoptado en la industria manufacturera (Ivanovna y López, 2018). Para el caso de los consumos específicos de energía y consistencia se presentan dos pares de valores equivalentes, el primero indica su valor de nivel en una escala -1 y +1 , y el segundo, entre corchetes, su valor en las respectivas unidades (Tabla 3).

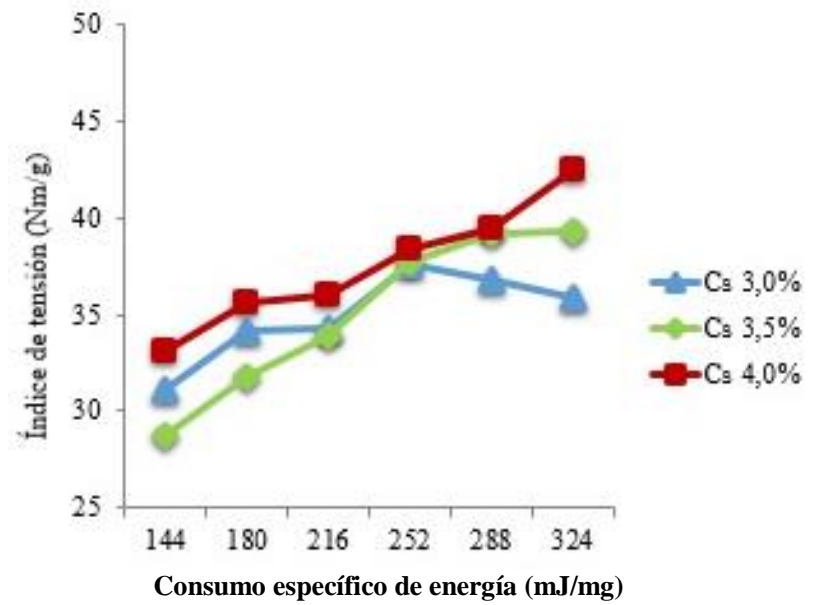

(a)

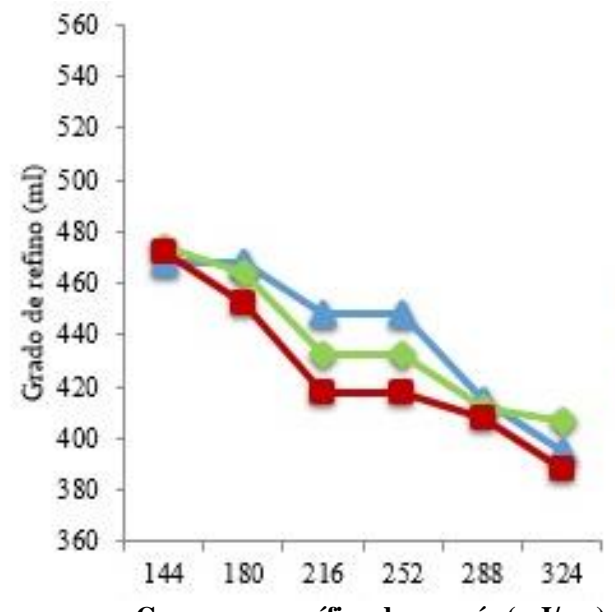

Consumo específico de energía $(\mathrm{mJ} / \mathrm{mg})$

(c)

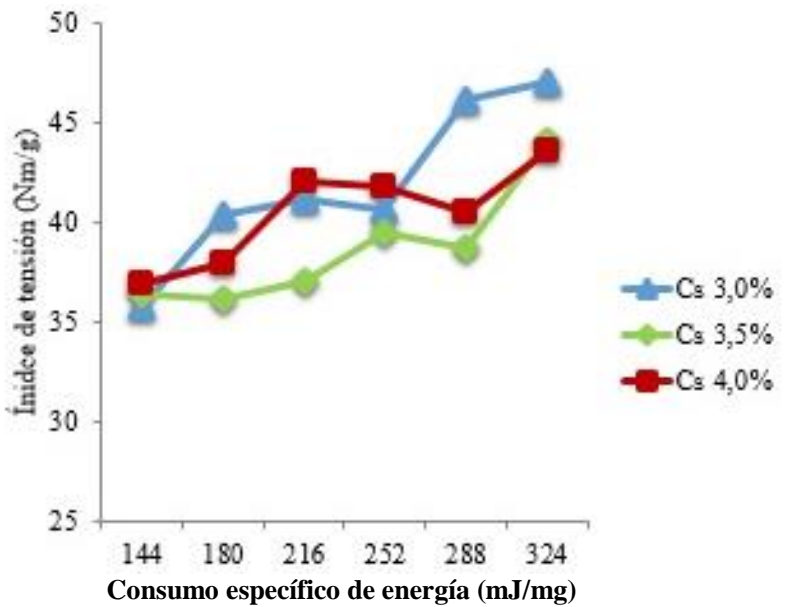

(b)

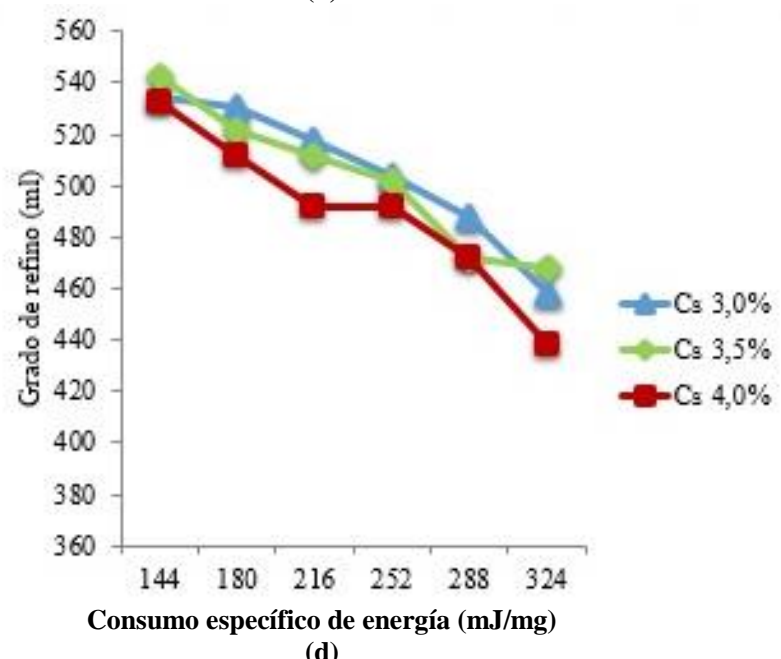

Figura 6. Curvas de refinación con fibra corta para índice de tensión sin enzima de refinación (a) y con enzima de refinación (b), y para grado de refino sin enzima de refinación (d) y con enzima de refinación (d).

Las curvas de refinación para fibra larga permitieron conocer el efecto que produce la utilización de enzima Quimizine B sobre las variables del grado de refino e índice de tensión (Figuras 6a, 6b, 6c y 6d), al diseñar tratamientos con seis niveles diferentes de consumo específico de energía, tres niveles de consistencia y dos tipos de fibra. En este sentido, la obtención de curvas de refinación ofrecen un aporte para verificar tendencias en propiedades 
físicas del producto final en la industria del papel, como fueron utilizadas en Escoto et al. (2015) para el caso del papel bond, y en Bassa y Sacon (2005) para el caso de papeles para imprimir y escribir. Con relación a los resultados de los modelos matemáticos ajustados para el índice de tensión y grado de refino, para los casos de uso de fibra corta y larga, los coeficientes de determinación oscilaron entre 84,5 y 96,3\% para el papel tisú, valores que resultan superiores en aproximadamente un $100 \%$ a los presentados en Parra (2011), en estudios de evaluación de celulosa de pino y eucalipto. Los resultados experimentales mostraron correlaciones negativas para los índices del grado de refino y correlaciones positivas en los índices de tensión, independientemente de que se considere o no la utilización de la enzima. Para el caso de refinación con fibra larga, el efecto del uso de la enzima Quimizine B ocasionó un aumento medio de 11,$3 ; 3,9$ y $2,9 \%$ en los índices del grado de refino del papel tisú, al experimentar con consistencias del 3,0; 3,5 y 4,0 \%, respectivamente (Figuras 6a, 6b, 6c y 6d). De la misma manera, la aplicación de la enzima produjo un aumento sobre el índice de tensión de un 11,4 y 9,6 \% para consistencias del 3,5 y 4,0 \%, respectivamente. Sin embargo, el índice de tensión disminuyó en un 5,3 \% cuando se experimentó con una consistencia del $4,5 \%$.

Las propiedades del grado de refino e índice de tensión no se mantuvieron constantes cuando varió el consumo específico de energía entre 144 y $324 \mathrm{~mJ} / \mathrm{mg}$. Una limitación de la presente investigación es que no se consideraron en la experimentación otras propiedades del papel, como por ejemplo la capacidad de absorción de agua y/o el volumen específico del papel tisú, lo cual pudiera ser incluido en estudios futuros para comprobar la validez de los resultados obtenidos.

\section{Conclusiones}

La utilización del diseño factorial multinivel es una técnica efectiva para identificar la significancia que presentan los factores e interacciones en los resultados del grado de refino e índices de tensión, en el proceso de refinación de papel tisú al utilizar materia prima con fibra larga y corta, a su vez, esta técnica permite identificar el nivel en que se debe configurar el consumo específico de energía y la consistencia de la pulpa, para obtener determinados resultados de resistencia y grado de refino del papel tisú. Los factores de operación más significativos que tienen incidencia en el grado de refino de la pulpa e índices de tensión en el papel tisú al utilizar fibra corta, fibra larga y la enzima de refinación Quimizine B, son el consumo específico de energía y la consistencia de la pulpa.

La variabilidad en la grado de refino de la materia prima para fibra corta y fibra larga, presentó coeficientes de variación de 1,08 y 2,03 \%, respectivamente. Las curvas de refinación resultantes aportan evidencia empírica para visualizar más fácilmente el comportamiento del grado de refino e índices de tensión del papel tisú, al aplicar seis tipos de consumos específicos de energía y niveles para la consistencia de la pulpa, además, a través de estas curvas de refinación se puede comprobar el efecto positivo que produce la utilización de la enzima de refinación, Quimizine $\mathrm{B}$, en la mejora de las propiedades del grado de refino e índice de tensión en el papel tisú al incluir fibra larga o fibra corta en la materia prima.

Los resultados de tensión y del grado de refino permiten conocer valores óptimos de consumo específico de energía y de consistencia de la pulpa en el proceso de refinación, para lograr un óptimo individual y óptimo simultáneo para estos indicadores, o propiedades del papel tisú.

\section{Referencias Bibliográficas}

Aguilar, N. (2016). Sugarcane bagasse pulp with a high ratio of long fiber. Revista Técnica de la Facultad de Ingeniería, Universidad de Zulia, 39(2), 47-55.

Angarita, J., Díaz, D., Lozano, L. (2009). Fibra de palma africana (elaeis guineensis) para mejorar las propiedades mecánicas del cartón reciclado. Revista ION, 22(1), 63-71.

Bassa, A., Sacon, V. (2005). Selección y caracterización de clones de eucalipto considerando parámetros silviculturales, tecnológicos y de producto final. Revista Celulosa y Papel, 21(2), 1-15.

Bhat, M. (2000). Cellulases and related enzymes in biotechnology. Biotechnology Advances, Biotechnol. Adv., 18(2000), 355-383. 
Buendía, E. (2013). El papel de la Ventaja Competitiva en el desarrollo económico de los países. Análisis Económico, 69, 55-78.

Cadena, E. (2008). Estudio del refinado de pastas de papel utilizando métodos biotecnológicos (enzimas). Tesis doctoral. Terrassa: Universidad Politécnica de Cataluña.

Coimbra, S., Lima, S. (2018). Análise de mercado e nível de concentração da indústria de papel tissue no Brasil. Revista Produção Online, 18(1), 165-188.

Colson, J., Bauer, W., Mayr, M., Fischer, W., Gindl, W. (2016). Morphology and rheology of cellulose nanofibrils derived from mixtures of pulp fibres and papermaking fin. Cellulose, 23(4), 2439-2448.

Contreras J. (2013). Propuesta de mejora de la producción y calidad mediante la creación de un nuevo sistema de preparación de pulpa para papel en la empresa papelera Asuncorp S.A. Tesis de grado. Guayaquil: Universidad de Guayaquil.

De Assis, T., Pawlak, J., Pal, L., Jameel, H., Venditti, R., Reisinger, L. W., Kavalew, D., Gonzalez, R. W. (2019). Comparison of wood and non-wood market pulps for tissue paper application. BioResourcesBioRes, 14(3), 67816810 .

Delgado, M., Recas, E., Puig, J., Arbat, G., Pereiras, M., Vilaseca, F., Mutjé, P. (2015). Aplicación de celulosa nanofibrilada, en masa y superficie, a la pulpa mecánica de muela de piedra: una sólida alternativa al tratamiento clásico de refinado. Maderas, Ciencia y Tecnología, 17(2), 97-107.

Escoto T., Murillo R., Rodríguez A., Anzaldo J., Rivera, J. (2015). Obtención de celulosa blanqueada de Ricinus communis L. mezclada con fibra industrial para fabricar papel bond. Revista Mexicana de Ciencias Forestales, 6(28), 106-125.

Escoto, T., Morales ,S., Rodríguez, A., Anzaldo, J. (2010). Diseño factorial de un proceso alcalino para obtener celulosa de higuerilla (Rricinus communis i.) y sus aplicación en cartón ondulado. ConcCiencia Tecnológica, 40(2010), 15-19.

Gigac, J., Fiserova, M. (2008). Influence of pulp refining on tissue paper properties. Tappi Journal, 7(8), 27-32.

Gutiérrez, H., De la Vara, R. (2012). Análisis y diseño de experimentos. México, DF: McGrawHill.

Hernández, R., Fernández, C., Baptista, M. (2014). Metodología de la investigación. México DF: McGrawHill.

Hines, W., Montgomery, D., Goldsman, D., Borror, C. (2014). Probabilidad y estadística para ingeniería y administración. México, DF: Equipo Editorial Patria.

ISO 5269-1. (2005). Pulps: Preparation of laboratory sheets for physical testing. Part 1: Conventional sheet-former method. ISO 5269-1:2005 Geneva: International Organization for Standardization (ISO).

ISO 5276-2. (2001). Pulps. Determination of drainability. Part 2: Canadian Standard freeness method. ISO 52672:2001 Geneva: International Organization for Standardization (ISO).

ISO. (2013). Sampling procedures for inspection by variables. Part 1: Specification for single sampling plans indexed by acceptance quality limit (AQL) for lot-by-lot inspection for a single quality characteristic and a single $A Q L$. ISO 3951-1:2013. Geneva: International Organization for Standardization (ISO).

Ivanovna, S., López, V. (2018). Elección de la función de deseabilidad para diseños óptimos bajo restricciones. Revista EIA, 15(30), 13-24. 
JIS Z 9031. (2012). Procedure for random number generation and randomization. JIS Z 9031. Tokyo: Japanese Industrial Standards (JIS).

Luiz da Silva, C. (2005). Competitividade da indústria exportadora brasileira de papel de imprimir e escrever: uma análise da inovação sob a ótica da cadeia de valor. Revista Produção, 5(3), 1-26.

Montgomery, D. (2019). Design and analysis of experiments. $10^{\text {th }}$ ed. Nueva Jersey: Wiley.

Parra, C. (2011). Evaluación de fibras celulosicas producidas en planta de celulosa Nueva Aldea. Tesis de maestría. Minas Gerais: Universidade Federal de Viçosa.

Robles, N., Sauceso, A., Delgado, E., Sanjuán, R., Turrado, J. (2014). Efecto de las microfibras de celulosa sobre papel con alto contenido de fibra reciclada. Revista Mexicana de Ciencias Forestales, 5(24), 70-79.

Statgraphics. (2017). Manual de usuario statgraphics centurion 18. Madrid: Statgraphics Technologies, Inc.

Torres, L., Melo, R., Colodette, J. (2005). Pulpa kraft blanqueada a partir de Pinus tecunumanii. Bosque, 26(2), 115122.

Valiente, C. (2013). Modelamiento del proceso de secado de papel tisú caso real planta Talagante, CMPC. Tesis de grado. Santiago: Universidad de Chile.

Villarreal, F., Gómez, J. Villarreal, M. (2014). La cultura organizacional y las estrategias competitivas en la industria de celulosa, cartón y papel en México. AD-minister, 25, 97-107. 


\section{REVISTA TECNICA}

DE LA FACULTAD DE INGENIERIA

UNIVERSIDAD DEL ZULIA

Vol. 45. №1, Enero - Abril, 2022

Esta revista fue editada en formato digital y publicada en Diciembre 2021, por el Fondo Editorial Serbiluz, Universidad del Zulia. Maracaibo-Venezuela

www.luz.edu.ve

www.serbi.luz.edu.ve

www.produccioncientificaluz.org 